\title{
Seguridad y violencia en América Latina en la segunda mitad del siglo XX. Militarismo y Guerra Fría
}

\section{Security and Violence in Latin America in the Second half of the $20^{\text {th }}$. Century. Militarism and Cold War}

\section{Segurança e violência na América Latina na Segunda Metade do Século XX. Militarismo e a Guerra Fria}

\author{
Maité Cristina Loría-López \\ Estudiante \\ Maestría Estudios Latinoamericanos \\ Instituto de Estudios Latinoamericanos \\ Universidad Nacional, Costa Rica \\ Doi: https://doi.org/10.15359/tdna.35-66.5 \\ Recibido: $15 / 07 / 19$ \\ Aceptado: 10/09/2019
}

\section{Resumen}

Este artículo explora la doctrina de seguridad y su reformulación, las guerras de baja intensidad (GBI), como estrategias fundadas en la necesidad territorial y política estadounidense de mantenerse en el poder a costa de las posibilidades de autogestionamiento de América Latina, las cuales

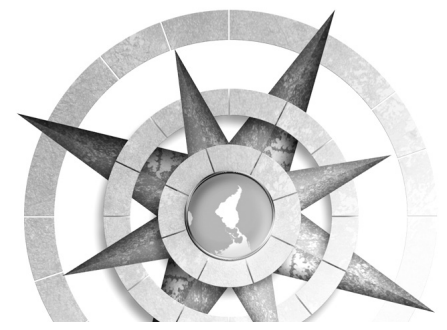


terror, la manipulación de las masas, el desplazamiento de miles de personas, el genocidio institucional, el abarcamiento de todas las herramientas de progreso, y el fallo absoluto de Estados como cohesores socioculturales y promotores de la paz conllevan la construcción de una cultura de violencia latinoamericana. A pesar de las medidas intercontinentales y la aplicación de las políticas de Mano Dura o la Guerra contra las drogas, los resultados han sido negativos y las consecuencias han profundizado las redes del crimen organizado, la violencia, la crisis económica de los Estados y la desconfianza en los mismos. De manera que la violencia en América Latina no se puede medir regionalmente ni combatir de forma unilateral, al contrario, debe manejarse localmente con un esfuerzo estatal y comunitario interdependientemente.

Palabras clave: doctrina de seguridad, política exterior estadounidense, guerras de baja intensidad, estados terroristas, violencia estructural, imperialismo

\section{Abstract}

This article explores the National Security Doctrine and its reformulation, the Low Intensity Conflicts (LIC), as strategies based on the US territorial and political need to impose their power at the expense of the possibilities of Latin America's self-management, which have prevailed due to an old creole militarism and a fragmented classist society whose vertical and destructive power relations are rooted in the construction of nation-states. This Latin American class-system and imperial historicity has led to the destruction of communities, cultures and exploitation of resources and people, through impunity exercised by Terrorist States and the institutionalization of structural violence. The violence experienced in times of war, the institutionalization of terror, the manipulation of the masses, the displacement of thousands of people, the institutional genocide, the encompassing of all the tools of progress, and the absolute failure of nation-states to inculacate sociocultural cohesion and promote peace, entails the construction of a culture of violence in Latin America. Despite the intercontinental measures and the application of the policies of Iron Fist or the War on Drugs, the results have been negative and the consequences have deepened the networks of organized crime, violence, the economic crisis of the states and distrust in the political structure altogether. Therefore, violence in Latin America cannot be measured regionally or combatted unilaterally, on the contrary, it must be managed locally with an interdependent effort by states and communities.

Keywords: national security doctrine, us foreign policy, low intensity conflicts, terrorist states, structural violence, imperialism.
76 Seguridad y violencia en América Latina en la segunda mitad del siglo XX. Militarismo y Guerra Fría Maité Cristina Loría-López

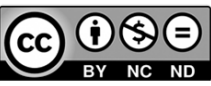

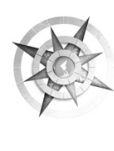




\section{Resumo}

Este artigo explora a doutrina de segurança e sua reformulação - guerra de baixa intensidade (LIW) - como estratégias baseadas na necessidade territorial e política dos EUA de permanecer no poder em detrimento das possibilidades de autogestão da América Latina, que conseguiram se impor à Nossa América devido a um velho militarismo crioulo e a uma sociedade de classes fragmentada, cujas relações de poder verticais e destrutivas estão enraizadas na construção de estados-nação. Esta classe latino-americana e esta historicidade imperialista levou à destruição de comunidades, culturas e à exploração de recursos e povos, através da impunidade exercida pelos Estados terroristas e da institucionalização da violência estrutural em Nossa América. A institucionalização do terror, a manipulação das massas, o deslocamento de milhares de pessoas, o genocídio institucional, a adoção de todas as ferramentas do progresso e o absoluto fracasso dos Estados como coesos socioculturais e promotores da paz levam à construção de uma cultura latino-americana de violência. Apesar das medidas intercontinentais e da aplicação das políticas de Mano Dura ou da Guerra às Drogas, os resultados têm sido negativos e as consequências têm aprofundado as redes do crime organizado, a violência, a crise econômica dos Estados e a desconfiança neles. Assim, a violência na América Latina não pode ser medida regionalmente ou combatida unilateralmente; pelo contrário, deve ser tratada localmente com um esforço estatal e comunitário que seja interdependente.

Palavras chave: Conselho de Segurança, política externa dos EUA, guerra de baixa intensidade, Estados terroristas, violência estrutural, imperialismo.

La construcción de los Estados-nación latinoamericanos bajo el mando de ejércitos y políticos criollos, junto a su debida herencia colonial de desigualdad, violencia y segregación (Álvarez, 2018; Cuevas, 2012; Solís y Moriconi, 2018), son las semillas desde donde nace la cultura de la violencia en Latinoamérica y las bases del asentamiento de un viejo militarismo (Leal, 2003) cuyas ideologías y accionares predominan en nuestras sociedades hoy. De acuerdo con Leal (2003), este viejo militarismo dejó a las élites militares con una sensación de derecho de ocupar un espacio preeminente en las sociedades nuestroamericanas, como fundadores y protectores de las mismas. Un autoritarismo político-militar, de corte darwiniano del siglo XIX, cuyas ideologías y prácticas:

No sufrieron cambios significativos con el nuevo orden internacional creado por la Segunda Guerra Mundial, hacían énfasis en la concepción orgánica del Estado, el carácter estratégico de 
los recursos naturales y las fronteras, y el conflicto potencial entre países vecinos, motivado por la competencia por el control del espacio y los recursos limitados. (Leal, 2003, p. 77)

Al finalizar la Segunda Guerra Mundial, la Guerra Fría divide al mundo en una bipolaridad ideológica (Leal, 2003). El poderío militar estadounidense y su ideología de seguridad nacional y, por ende, del continente americano, construyen políticas de autoprotección continental que llevan a la firma del Acta de Chapultepec en 1945, donde se promueve la defensa colectiva del continente ante los enemigos de la democracia y el progreso, es decir el comunismo (Calloni, 1994; Leal, 2003). En 1946, el Plan Truman propone la unificación militar continental y en 1947 se firma el Tratado Interamericano de Asistencia Recíproca (TIAR), que integra las políticas militares del continente; Estados Unidos promulga en el mismo año el Acta de Seguridad Nacional, que vendrá a convertirse en la doctrina de seguridad nacional, la cual aplica la ley de contención ${ }^{1}$ a la Unión Soviética (Leal, 2003).

En este contexto, en 1948 se funda la Organización de Estados Americanos (OEA) con el fin de mantener el piso

1 Estrategia de modificación de conductas políticas, militares y económicas por medio de "disuasiones y recompensas” (Leal, 2003, p. 74, citando a Lewis, 1992). jurídico-político de estas actas y tratados; lo que conlleva a que se firme el Memorando 68 en 1950, que propone la estrategia militar internacional de los EE.UU, cuya sombrilla cubre la región latinoamericana y desemboca en los programas de ayuda militar (MAPs) entre 1952 y 1958. Los MAPs son el adiestramiento militar $^{2}$ de las tropas latinoamericanas "en Estados Unidos y más tarde en la Zona del Canal en Panamá, (que) contribuyó a la transferencia de la concepción norteamericana de seguridad nacional a los ejércitos de la región" (Leal, 2003, p. 78). Las estrategias militares estadounidenses penetraron violenta y efectivamente en el territorio suramericano gracias a su fértil tierra militarizada e institucionalizada en las organizaciones castrenses sociopolíticas; y en centroamérica por medio de intervenciones militares.

Ese modelo parte de considerar un mundo anárquico, en el cual cada Estado- nación es responsable de su propia supervivencia, al confiar sólo en sí mismo para protegerse de los demás. Plantea además la necesidad de mantener el statu quo como la situación más segura, tanto en el plano nacional como en el internacional. En este último plano, propende por el sostenimientodelordenjerárquico

2 En Costa Rica, de acuerdo con Álvarez (2018), la policía recibió entrenamiento contrainsurgente estadounidense en la Base Militar del Murciélago.
78 Seguridad y violencia en América Latina en la segunda mitad del siglo XX. Militarismo y Guerra Fría Maité Cristina Loría-López

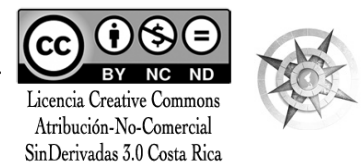


y las posturas hegemónicas. La tutela hegemónica se justifica al considerar que la democracia sólo es posible en los Estados modernos. (Leal, 2003, p. 78)

\section{La doctrina de seguridad nacional y las dictaduras terroristas en la segunda mitad del siglo XX}

En vísperas de la Revolución cubana en 1959, el bipolarismo entre el continente unido americano en contra del comunismo y el deseo de autogestionarse enmarcando las condiciones de la Guerra Fría latinoamericana, lo que justifica la política estadounidense para con la región "inestable y problemática" (Sweedler, p. 415), acreditando la creación de la Alianza del Progreso "contra la pobreza, y los programas ampliados de contrainsurgencia (Fuerzas Especiales del Ejército y Oficina de Ayuda para la Seguridad Pública) contra la subversión" (Leal, 2003, p. 79), junto con la estrategia militar de contención y disuasión.

De forma que en América Latina, las políticas de seguridad nacional de EEUU se transforman en la doctrina de la seguridad nacional con la percepción de que el comunismo en esta región se debe pelear internamente y esto requiere la militarización del Estado y la sociedad. "El apoyo (EEUU) a las dictaduras militares fue la manera más expedita para la aplicación de estos principios. Los pocos gobiernos legítimos pero inestables de América Latina se dejaron llevar por la tutela estadounidense y abandonaron su función de orientar la política militar" (Leal, 2003, p. 78). De forma que, la doctrina es desarrollada por "circunstancias ideológicas y políticas externas a la región y a las instituciones castrenses mismas" (Leal, 2003, p. 75, cursiva mía). Se despierta el viejo militarismo latinoamericano y reiteran el discurso de libertadores y creadores de los Estados-nación para justificar la toma del Gobierno, los golpes de Estado y el asentamiento de las dictaduras militares. La doctrina justifica la necesidad de las intervenciones militares en contra de las amenazas internas al "progreso y la democracia", convirtiendo a adversarios políticos en enemigos y construyendo Estados terroristas que perpetúan todo tipo de violaciones a los derechos humanos en nombre de la democracia (Calloni, 1994; Cuevas, 2012; Leal, 2003). "Nació así el Estado Contrainsurgente, que privilegia la función de los aparatos armados sobre cualquiera de las otras instituciones que lo componen, y que ejercen sistemáticamente el terrorismo de Estado, basado en la institucionalización de la Doctrina de la Seguridad Nacional" (Cuevas, 2012, p. 149, cursiva mía ).

En América del Sur, la adopción de la doctrina llevó a la creación secreta 
del Plan Cóndor ${ }^{3}$, cuyo propósito era la abolición del comunismo en la región y bajo esta justificación se convirtió en un proyecto interestatal de terror, tortura, asesinatos y desapariciones de cualquier adversario político o civil, comunista o populista que levantara la voz contra las dictaduras militares y sus constantes violaciones de derechos humanos. No fue hasta 1992, al encontrarse los Archivos del Terror en Paraguay, que se comprobó la organización de inteligencias suramericanas por mantener control político y militar so-

3 “"El Operativo Cóndor” es el nombre en clave para la recolección, intercambio y almacenamiento de información secreta relativa a los denominados "izquierdistas", comunistas y marxistas, que se estableció recientemente entre los servicios de inteligencia en América del Sur, con el fin de eliminar las actividades terroristas marxistas en la región. Además, "Operativo Cóndor" tiene previstas operaciones conjuntas contra objetivos terroristas en los países miembros. Una tercera fase, y más secreta, del "Operativo Cóndor" implica la formación de grupos especiales de los países miembros, que deberán viajar por cualquier parte del mundo hacia países no-miembros, para llevar a cabo castigos incluido el asesinato contra terroristas o simpatizantes de organizaciones terroristas de los países miembros del "Operativo Cóndor". Por ejemplo, en el caso de que un terrorista o simpatizante de una organización terrorista de un país miembro del "Operativo Cóndor" se encontrara en un país europeo, se enviaría un grupo especial del "Operativo Cóndor" para localizar y vigilar al objetivo. Cuando hubiera terminado la operación de localización y vigilancia, se enviaría un segundo grupo del "Operativo Cóndor" para llevar a cabo el castigo real contra el objetivo. Los grupos especiales serían provistos de documentación falsa de los países miembros del "Operativo Cóndor"” (Calloni, 1994). bre la región, junto con la participación de los EEUU. ${ }^{4}$

Los archivos detallan el destino de cientos, quizá miles, de latinoamericanos secretamente secuestrados, torturados y asesinados por los regímenes derechistas de los años setenta. También ofrecen una pista en papel que confirma la existencia de una conspiración escurridiza y sanguinaria entre los servicios de Argentina, Bolivia, Brasil, Chile, Paraguay y Uruguay para rastrear y eliminar a los adversarios políticos con independencia de las fronteras nacionales. Ahora es posible completar el esbozo del "Operativo Cóndor", tal como se conocía a esta red ilícita (Calloni, 1994).
4 "Estados Unidos proporcionó la inspiración, el financiamiento y la asistencia técnica para la represión y puede haber plantado la semilla que desembocaría en el Operativo Cóndor. La CIA facilitó una mayor coordinación entre los servicios de inteligencia de la región... La CIA también organizó encuentros entre líderes de los escuadrones de la muerte brasileños con argentinos y uruguayos... El asesoramiento y la ayuda de Estados Unidos facilitaron la coordinación entre los servicios de inteligencia regionales. Esta cooperación hizo posible el intercambio de información y prisioneros e incluso asesinatos conjuntos. Un exiliado político podía ser mantenido como rehén o secuestrado y llevado a través de las fronteras, torturado y desaparecido, sin ninguna autorización judicial" (Calloni, 1994).
80 Seguridad y violencia en América Latina en la segunda mitad del siglo XX. Militarismo y Guerra Fría Maité Cristina Loría-López

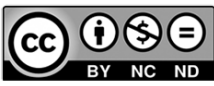

Licencia Creative Commons Atribución-No-Comercial SinDerivadas 3.0 Costa Rica 
Hasta ese momento, eran las Abuelas de Plaza de Mayo las que arriesgaban sus vidas protestando en las calles, recolectando información sobre desaparecidos y dándose la tarea de buscar la niñez tomada de padres o madres comunistas o socialistas y restituirlos con sus debidas familias, o los sobrevivientes de las mismas. Fueron estos movimientos sociales los que mantuvieron la memoria colectiva de los horrores vividos durante las dictaduras, demandando justicia por las violaciones de derechos humanos. Si no fuera por su trabajo, no sería posible la recolección de datos y testimonios que nos permiten comprender las vivencias bajo los Estados militares de la segunda mitad del siglo XX por medio de investigaciones, documentales y literatura.

La Doctrina de Seguridad Nacional en América Latina fue, ante todo, un planteamiento ideológico y político que responde a una racionalidad mecánica y ante todo militar, que fue ejecutada por medio de golpes de Estado... este lastre dificulta la tendencia de fortalecimiento de la sociedad civil frente al Estado y la necesidad de solucionar los innumerables problemas de integración social. Este es el máximo reto de la denominada democracia liberal, modelo vigente de Estado-nación. (Leal, 2003, p. 85)
En los años sesentas, la ideología de la seguridad nacional estadounidense se extiende hasta la protección de acceso y bienestar del mercado de EEUU (Elbaum, 2018; Leal, 2003; Sweedler, p. 408). Es posible ver esto claramente en el golpe de Estado guatemalteco al presidente Jacobo Árbenz en 1954, gestionado por la Central Intelligence Agency (CIA), cuya revolución agraria demandaba la toma por el pueblo de extensos monocultivos, de los cuales algunos le pertenecían a la United Fruit Company (UFCo)..$^{5}$ En Centroamérica, donde la doctrina se implementó por medio de intervenciones militares, las clases políticas toleraban a los militares reconociendo su utilidad y abandonando el campo de la política militar, dejándolo bajo la influencia estadounidense del estado de seguridad, "de hecho desarrollaron una visión mundial abiertamente totalitaria con consecuencias mortales" (Calloni, 1994). De acuerdo con Cuevas (2012), "Guatemala ha sido considerada el laboratorio de la contrainsurgencia en América Latina" (p. 151). En los años sesentas, el Estado militar acabó con todos los comités agrarios y la legislación social del presidente Árbenz, a finales de los años setentas habían aniquilado "a la primera guerrilla surgida en el país

5 De acuerdo con Álvarez (2018) en el 2001 y en el 2013 Randall Muñoz y Gerardo Moya respectivamente fueron asesinados con armas policiales en conflictos de tenencia con la United Fruit Company.

6 Citando el documento La batalla por Guatemala (1994). 
en 1962" (Cuevas, 2012, p. 150) y en los ochentas se desmantelaron todas las organizaciones que mantenían el movimiento guerrillero vivo; fue en esta última oleada de terror que el Gobierno militar guatemalteco puso a prueba "dispositivos de control social genocidas" (Cuevas, 2012, p. 150). En el contexto latinoamericano, la porosidad de la doctrina en las políticas de la región responde a la necesidad de mantener el statu quo de las clases dominantes en contra de los movimientos populistas y aquellos que históricamente han sido dominados (Cuevas, 2012; Elbaum, 2018; Leal, 2003).

Esta preservación de estructuras sociales tradicionales permitió que Alain Touraine afirmara que en América Latina el mantenimiento de los privilegios suele primar sobre la tasa de ganancias. En momentos de inestabilidad e incertidumbre, el golpe de Estado militar al servicio del statu quo garantizaba el mantenimiento de las relaciones de dominación y la exclusión social y política. El intervencionismo militar en América Latina no niega el apego ideológico y abstracto a las instituciones de la democracia occidental que ha caracterizado a esta región. Muchas intervenciones se han justificado en nombre de la democracia y la defensa de las instituciones y la constitución. Este comportamiento hace parte del carácter abstracto de respeto por la democracia, pues sólo así quienes proclaman estos principios pueden ser los mismos que los transgreden. (Leal, 2003, p. 83)

\section{Guerras de baja intensidad: el nuevo modelo intervencionista estadounidense}

La formulación de esta doctrina respondió a la creciente necesidad -percibida por los Estados Unidos- de fortalecerse en sus compromisos extranjeros frente al poderío de la URSS. Constituyó entonces, una herramienta política y militar que favoreció el logro de la política intervencionista norteamericana durante la administración Reagan, y estuvo destinada a establecer la "re- hegemonización” mundial que los EEUU quería imponer en la última etapa de la Guerra Fría (Kreibohm, 2008, p. 82)

En 1973, las tropas estadounidenses se retiran de las tierras vietnamitas dejando un saldo de 700.000 soldados muertos en el conflicto armado y un descontento social seguido de una creciente desconfianza política.

Con la oleada social del pacifismo estadounidense en los años setentas y basado en este consenso social por evitar intervenciones militares estadounidenses en el extranjero, hay un intento por parte del presidente Jimmy Carter (1977-1981)
82 Seguridad y violencia en América Latina en la segunda mitad del siglo XX. Militarismo y Guerra Fría Maité Cristina Loría-López

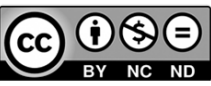

Licencia Creative Commons Atribución-No-Comercial SinDerivadas 3.0 Costa Rica

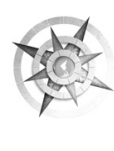


de limitar el apoyo a los militares latinoamericanos bajo el discurso de derechos humanos (Kreibohm, 2008; Leal, 2003; Sweedler, s.f.). Es importante anotar que en 1976, Orlando Letelier, exministro de Defensa y de Relaciones Exteriores del presidente chileno Salvador Allende, fue asesinado por medio de un carro bomba en la rotonda Sheridan en las afueras de la Embajada Row de Washington, lo que puso en el mapa internacional las acciones, que por décadas se habían pasado por alto, del infame Plan Cóndor (Calloni, 1994): "Hacia finales de los años setenta, el Cono Sur se encontraba en lo más profundo de la represión y sólo un reducido grupo de activistas y periodistas se atrevía a hacer frente a los regímenes militares" (Calloni, 1994).

Cuando las acciones de la inteligencia militar y autoritaria del Cono Sur comenzaron a vengar a sus objetivos en tierras estadounidenses y europeas, el periodismo y los noticieros internacionales finalmente giraron su mirada a la región, cuyas vivencias bajo la opresión militar y el terrorismo estatal institucionalizado habían sido ignoradas por décadas.

A pesar de ello, el triunfo de la Revolución Sandinista nicaragüense en 1979, el comienzo de la guerra civil en el Salvador (1980-1992), junto con la reanudación de la Guerra Fría durante el Gobierno de Ronald Reagan (1981-1989), llevan al replanteamiento de estrategias de guerra y políticas de seguridad esta- dounidenses (Kreibohm, 2008; Leal, 2003). Reagan y su Gobierno se plantean la forma de reemprender su dominio sobre las tierras latinoamericanas y su imagen como potencial mundial. En 1986, las intervenciones militares se reformulan bajo el nombre de guerras de baja intensidad (GBI) (Kreibohm, 2008; Leal, 2003). Los ochentas son categorizados por un intento de re-democratizar América Latina, lo que deja a las instituciones y clases castrenses con una crisis identitaria y la necesidad de reformular su poderío dentro de las existentes instituciones democráticas, es decir, la política y/o la economía.

La guerra como resolución de conflictos se hace obsoleta entre potencias, pero se intensifica interna e internacionalmente en el sur, convirtiendo la Guerra Fría en una Guerra Caliente Latinoamericana (Leal, 2003, p. 82). La ideología de las GBI se alimenta de las victorias y las estrategias revolucionarias para crear tácticas militares del mismo calibre de contraataque: "Estos conflictos son de tipo mixto; en ellos se combinan los aspectos políticos y los militares, por lo tanto para responderlos se hace necesaria una respuesta integral" (Kreibohm, 2008, p. 77). Esto lleva a la utilización de técnicas insurgentes para derribar Gobiernos enemigos y estrategias de manipulación de comunidades para contrarrestar el apoyo a movimientos revolucionarios. 
Algunos de estos elementos, actualizados en las circunstancias del siglo XXI y las llamadas guerras híbridas, se pueden observar, por ejemplo, con las recientes acusaciones falsas contra el presidente Luiz Inácio Lula da Silva, que desembocaron en la elección del ultraderechista Jair Bolsonaro.

\section{El Conflicto de Baja Intensidad es una lucha político-militar li- mitada para alcanzar objetivos políticos, sociales, económicos o psicológicos. Es muchas veces prolongado y varía de presiones diplomáticas, económicas y psi- co-sociales hasta el terrorismo y la contrainsurgencia. El conflicto de baja intensidad generalmente se limita a un área geográfica y muchas veces se caracteriza por constreñimientos en las armas, tácticas y nivel de violencia (Krei- bohm, 2008, p. 78, citando el Analytical Review of Low-Intensity Conflict, 1986)}

Los conflictos de baja intensidad son diversos como los conflictos mismos y aplica de igual forma para sus estrategias de manejo. Cubren las siguientes operaciones:

1. Clásicas operaciones de contrainsurgencia que se manejaban durante la era de la doctrina de seguridad (Kreibohm, 2008),
3. operaciones proinsurgencia que se encargan de derribar Gobiernos que llegaron al poder por medio de las guerrillas,

4. operaciones contingentes en tiempos de paz que utilizan las fuerzas militares para reprimir "desórdenes sociales, intimidar a gobiernos hostiles, realizar operativos de asalto, ataque y recuperación, implementar operaciones de inteligencia y llevar a cabo muestras de poderío que respalden los objetivos de la política exterior norteamericana" (Kreibohm, 2008, p. 80),

5. operaciones antiterroristas preventivas y defensivas, ya que "el terrorismo (es construido como) un fenómeno específicamente relacionado con la ideología marxista-leninista, inspirado y patrocinado por la URSS y sus aliados" (Kreibohm, 2008, p. 81),

6. operaciones antidrogas, que desembocan en el discurso y la práctica de la guerra contra las drogas, donde se simboliza el mercado de drogas como un ataque a la seguridad estadounidense y se justifica la utilización de fuerzas armadas en el exterior bajo la necesidad de "atacar y destruir... fuentes de producción y distribución de narcóticos ilegales" (Kreibohm, 2008; Sweedler, s.f.), 2. 
7. operaciones de mantenimiento de la paz al comando de la Organización de Naciones Unidas (Kreibohm, 2008).

La doctrina de seguridad y su reformulación, las GBI, son estrategias fundadas en la necesidad territorial y política estadounidense de mantenerse en el poder a costa de las posibilidades de autogestionamiento de América Latina, la destrucción de comunidades, culturas y explotación de recursos y personas. Los Estados de seguridad o mejor llamados Estados sin derechos o Estados terroristas, han dejado sociedades quebrantadas (Álvarez et al., 2007) por las violencias vividas en los tiempos de guerras, la institucionalización del terror, la manipulación de las masas, el desplazamiento de miles de personas, el genocidio institucional, el abarcamiento de todas las herramientas de progreso y el fallo absoluto de Estados como cohesores socioculturales y promotores de la paz.

... las torturas y el homicidio, las violaciones y desapariciones generaron en la mente y el corazón de las personas víctimas de la guerra una manera diferente de estar en el mundo, caracterizada por el descontento, el dolor y el sufrimiento como formas de ver y explicar la vida: la cultura de la violencia (Cuevas, 2012, p. 173, citando a Chéster Urbina, 2010).
En 1992, se encuentran los Archivos del terror en Paraguay, demostrando "la existencia de una campaña de terror coordinada internacionalmente... 50.000 personas asesinadas, 30.000 desaparecidos y 400.000 encarcelados" (Calloni, 1994). Esta evidencia se convierte en una amenaza a los agentes políticos y militares que perpetraron las violaciones de derechos humanos durante las dictaduras de los setentas, y el involucramiento no solo militar, sino informativo de los EEUU, de forma que "se están realizando esfuerzos para eliminarlos o depositarlos en manos "seguras". Algunos de los documentos ya han desaparecido y existen sutiles maniobras para sustraer a los restantes del control legal y periodístico" (Calloni, 1994).

Esto demuestra el nivel de impunidad política y militar que se maneja en América Latina, y cómo esta impunidad ha sido institucionalizada en nuestros Gobiernos y leyes. De acuerdo con Calloni (1994), a pesar de las protestas en contra del manejo de los archivos por medio de la organización USAID, quienes ofrecieron 40 millones de dólares, son estos los que están asesorando al Centro de Documentación de Paraguay hoy en día. El caso guatemalteco y el salvadoreño sufren similares consecuencias, ha sido difícil traer a la Justicia a los responsables de los horrores de las dictaduras y las guerras civiles. Las vivencias de las 
guerras y las represiones han creado secuelas y divergencias sociales fuertes, detonando el uso de la violencia como una herramienta de subsistencia.

A finales de la Guerra Fría en los años noventa, se contextualizan las amenazas a la seguridad como problemas sociales transnacionales que justifican la continua utilización de estrategias de GBI en la región. Los sucesos del 2001 en Nueva York crean un nuevo enemigo contra la democracia, el terrorismo (Leal, 2003; Woo, 2007). De esta forma, a comienzos del siglo XXI, el narcotráfico, la corrupción, el terrorismo, las violaciones de los derechos humanos y la destrucción del medio ambiente son ejemplos de nuevas amenazas que requieren la utilización de medidas militares a nivel internacional (Leal, 2003; Sweedler, sf; Woo, 2007). Las estrategias son lideradas por los opresores y no tienen como fin real el establecimiento de la democracia ni de la paz.

\section{Violencia epidémica en América Latina a finales del siglo XX y principios del siglo XXI}

Las inequidades económico-sociales, profundizadas por las reformas neoliberales y la herencia de la guerra han desempeñado un papel determinante en esta situación. Ambas contribuyeron en el rompimiento del tejido social que daba sustento a la vida cotidiana y provocaron el surgimiento de una sociedad "desbocada" en la que la inseguridad es pan de todos los días. (Cuevas, 2012, p. 144)

A principios del siglo XXI, ya América Latina era considerada la región más violenta $^{7}$ del mundo (Cuevas, 2012; Jaitman, 2017; Rojas, 2008; Solís y Moriconi, 2018). A pesar de las medidas intercontinentales y la aplicación de las políticas de mano dura o la guerra contra las drogas, los resultados han sido negativos y las consecuencias han profundizado las redes del crimen organizado, la violencia, la crisis económica de los Estados y la desconfianza en los mismos (Álvarez et al., 2007; Kreibohm, 2008; Solís y Moriconi, 2018).

De acuerdo con Solís y Moriconi (2018), Álvarez (2018), Cuevas (2012) y Segato (2018), son la complicidad intraestatal y el mantenimiento de nichos institucionales de impunidad los que han agravado la violencia de América Latina. Debe tomarse en cuenta que estas prácticas antidemocráticas

7 "En esta zona, que acumulaba el 8\% de la población mundial, ocurrían el $40 \%$ de los homicidios con armas de fuego y el $66 \%$ de los secuestros del mundo. Entre el año 2000 y el 2010 la tasa de asesinatos en la región creció $11 \%$. En el mismo período, en el resto del mundo se estabilizó o descendió. Los asaltos se triplicaron en los últimos 25 años y se producían alrededor de 460 actos de violencia sexual por día. Ninguna otra región del planeta tiene índices de homicidios y delitos graves tan altos y continuos como América Latina" (Solís y Moriconi, 2018, p. 14).
86 Seguridad y violencia en América Latina en la segunda mitad del siglo XX. Militarismo y Guerra Fría Maité Cristina Loría-López

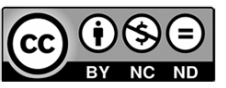

Licencia Creative Commons Atribución-No-Comercial SinDerivadas 3.0 Costa Rica

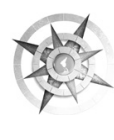


fueron institucionalizadas durante las dictaduras militares de los años sesentas y setentas, y re-institucionalizadas en los años noventa con la continua imposibilidad de traer a la Justicia a los partidarios del autoritarismo de la segunda mitad del siglo XX, incluyendo la responsabilidad de los actores estadounidenses. Sin embargo, estas relaciones de poder verticales y destructoras están enraizadas en la construcción de Estados-nación (Álvarez, 2018; Cuevas, 2012; Solís y Moriconi, 2018), dejándonos con una historia de violencia estructural, económica, social y cultural que desemboca en una región con altos déficits de cohesión social y manejo político de sus pueblos, instituciones y recursos (Rojas, 2008). Una región quebrantada por su historia y por las relaciones de poder, de clases y grupos, que se han asegurado su bienestar y poderío utilizando discursos democráticos y progresistas.

No es coincidencia que los actores sociales más afectados por estas formas de terrorismo sean ecologistas, campesinos e indígenas. El problema es estructural: conflictos por tierras: por tenerla o defenderla, y conflictos ambientales, han sido parte de un círculo de violencia que nos aleja de cualquier mito de paz y respeto a los Derechos Humanos en Costa Rica. (Álvarez, 2018, p. 73)
De acuerdo con el estudio de Solís y Moriconi (2018), las teorías que se toman la tarea de explicar el fenómeno de la violencia en América Latina varían entre Estados débiles o fallidos incapaces de "hacer cumplir la ley o, directamente, se encargan de que no se cumpla y venden protección a grupos criminales" (Solís y Moriconi, 2018, p. 17); y aquellos que denominan nuestros Estados latinoamericanos como Estados perversos: "La emergencia de una forma de Estado que, en su esencia, lleva implantada la violencia en pos de defender los intereses de élites particulares y su permanencia en el poder" (Solís y Moriconi, 2018, p. 17); y finalmente aquellos que ven la situación de violencia y del poderío intraestatal del crimen organizado como "estadotropismo" (Solís y Moriconi, 2018, p. 17) o un segundo Estado (Segato, 2018).

La violencia latinoamericana es tan compleja y diversa que es imposible de ser combatida con una serie de recetas universales. Probablemente este ha sido uno de los errores que determina que, tras casi dos décadas de estudios sobre la seguridad ciudadana y recomendaciones e implementación de políticas públicas, el problema se haya agravado en la región, mientras en el resto del mundo se estabiliza o disminuye (Solís y Mariconi, 2018, p. 23) 
La violencia en América Latina no se puede medir regionalmente, al contrario, debe manejarse localmente, porque toma diferentes formas y patrones dependiendo del espacio en el que está y los factores que dentro de él se formulan (Jaitman, 2017; Solís y Mariconi, 2018.); ya que ésta se ha convertido en un mecanismo para tener acceso a bienes materiales, protección y más que todo, el control sobre territorios (Barrios, 2016; Segato, 2018; Solís y Mariconi, 2018, p. 18). Tampoco se puede manejar la seguridad de afuera para dentro, o unilateralmente, pero debe ser un trabajo interdependiente (Rojas, 2008.).

Las redes de crimen organizado, las maras, el tráfico de drogas, armas y personas son ejemplos de mundos que sobreviven y acaparan territorios y poder por medio de la violencia. Como consecuencia, se agrava la migración masiva (Elbaum, 2018; Cuevas, 2018), la continuación de Estados impunes, el incremento de gastos de PIB en mantenimiento de cárceles y medidas de seguridad (Jaitman, 2017) y la incapacidad estatal o regional de América Latina de autogestionar sus recursos y politicas para el bienestar de sus pueblos. En tanto que continuemos aceptando políticas exteriores de guerra y control, permitimos que EEUU mantenga su poder sobre Nuestra América, y continúen reformulando sus políticas de seguridad pública en contra de nuestras personas y sin responsabilizarse de sus acciones en la región. Tal es el caso de las drogas y la migración (Woo, 2007), y es por esto que estamos viendo el incremento de violaciones de derechos humanos en la frontera México-Estados Unidos y también medidas de represión económica contra México como "el culpable de la porosidad de las fronteras".

Lo que es seguro es que estamos viviendo en un constante caos violento donde los más vulnerables son aquellos que más están alejados de la protección requerida y se convierten en las presas fáciles del crimen organizado y/o de las maras. Los jóvenes y la niñez, los adultos mayores y los migrantes son los más vulnerables. Hay que tomar en cuenta que las mujeres están dentro de todos estos subgrupos, y la violencia histórica y sistémica contra ellas está causando daños irreparables en nuestras sociedades, como la institucionalización del feminicidio (Cuevas, 2012; Guedes et al., 2014; Segato, 2018). Debemos buscar herramientas de autogestión, regionales e independientes de las ideologías represivas enmascaradas bajo discursos de derechos humanos, democracia y el progreso.
88 Seguridad y violencia en América Latina en la segunda mitad del siglo XX. Militarismo y Guerra Fría Maité Cristina Loría-López

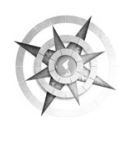




\section{Referencias bibliográficas}

Álvarez, A. M. et al. (2007, juliodiciembre). Difusión transnacional de identidades juveniles en la expansión de las maras centroamericanas. Perfiles Latinoamericanos, (30), 101-122

Álvarez, M. (2018, julio-diciembre). Los terrorismos a la tica. Casos y relatos que vinieron a mí. Temas de Nuestra América, Revista de Estudios Latinoamericanos 34 (64),67- 81. DOI: https://doi.org/10.15359/ tdna.34-64.5

Barrios, M. A. (2016). Geopolítica de la seguridad: crimen organizado y globalización. Alainet. Recuperado de : https://www.alainet.org/es/ articulo/181036

Calloni, S. (1994). Los Archivos del Horror. CovertAction. Recuperado de:

http://www.derechos.org/nizkor/doc/condor/calloni.html

Cuevas, R. (2012). Cultura y violencia: la cultura de la violencia. En De banana republics a repúblicas maquileras - La cultura en Centroamérica en tiempos de globalización neoliberal (1990-2010) (pp.141-186). San José: Editorial EUNED.
Elbaum, J. (2018). La larga marcha del hambre: éxodos del naufragio neoliberal. Sur y Sur, recuperado de: http://www.surysur.net/ la-larga-marcha-del-hambre-exodos-del-naufragio-neoliberal/

Guedes, A. et al. (2014, enero-marzo). Violencia contra las mujeres en Latinoamérica y el Caribe. Foreign Affairs Latinoamerica, 14 (1), 40-48.

Jaitman, L. (2017). Crimen conlleva altos costos sociales, públicos y privados en América Latina y el Caribe: Estudio BID. Comunicados de prensa, Banco Interamericano de Desarrollo. Recuperado de: https://www.iadb.org/es/noticias/comunicados-de- prensa/2017-02-03/cuanto-le-cuesta-el-crimen-a-america-latina\%2C11714.html

Kreibohm, P. (2008, enero-marzo). la doctrina de la guerra de baja intensidad: la formulación de una nueva categoría de conflicto. $\mathrm{Pa}$ deceme, (17), 73-84.

Leal, F. (2003, junio). La doctrina de seguridad nacional: materialización de la Guerra Fría e n América del Sur. Revista de Estudios Sociales, (5), 74-87. 
Rojas, F. (2008). Globalización y violencia en América Latina: debilidad estatal, inequidad y crimen organizado inhiben el desarrollo humano. Universidad para La Paz.

Solís, J. M. y Moriconi, M. (2018). La violencia letal en América Latina: un flagelo heterogéneo pero generalizado. En Atlas de la violencia en América Latina (pp. 13. 105). México: Universidad Autónoma de San Luis Potosí.

Segato, R. (2018). La Violencia contra las mujeres es sobre las mujeres contra la vida. Diálogo con Rita Segato. Fundación Rosa Luxemburgo. Biodiversidad: Recuperado de: http:// www.biodiversidadla.org/Documentos/La_violencia_contra las_mujeres_es__sobre_las mujeres_contra_la_vida._Dialogo_con_Rita_Segato
Sweedler, A. (S.f.) La política de seguridad de Estados Unidos en la post Guerra Fría.

Woo, O. (2007, enero-abril). La migración: un asunto de seguridad nacional en Estados Unidos en el siglo XXI. México y la Cuenca del Pacífico, 10 (28), 43-52. 